\title{
Assessing the prediction capacity of an agricultural supply positive mathematical programming model
}

\author{
Rui Manuel de Sousa Fragoso
}

Department of Management,

ICAAM, University of Évora,

Évora, Portugal

E-mail: rfragoso@uevora.pt

\section{Maria Leonor da Silva Carvalho*}

Department of Economics, ICAAM, University of Évora, Évora, Portugal

Fax: +351266740896

E-mail: leonor@uevora.pt

*Corresponding author

\section{Pedro Damião de Sousa Henriques}

Department of Economics, CEFAGE, University of Évora, Évora, Portugal

E-mail: pdamiao@uevora.pt

\begin{abstract}
In this paper, the calibration and prediction capacity of a supply response positive mathematical programming model (PMP) for the Alentejo region are evaluated. The model is calibrated with prices and agricultural subsidies of the base year (2000), using the specification rules of the cost function standard, Paris standard, average cost and exogenous elasticities. Then, the model is utilised for prediction of crop and livestock supply with prices and subsidies of 2004. Model results for 2000 and 2004 agricultural price and subsidies are compared, with available data, regarding optimal combination of activities to test model's capacity to reproduce Alentejo agricultural sector behaviour in response to the changes in prices and agricultural policy. Results showed that the PMP model reproduces exactly the observed activity levels on the base year, whatever the rule used to specify the cost function, and that PMP is an efficient instrument to predict agricultural supply, mainly using the exogenous elasticities specification rule.
\end{abstract}

Keywords: PMP; positive mathematical programming; Alentejo; agricultural sector.

Reference to this paper should be made as follows: Fragoso, R.M.S., Carvalho, M.L.S. and Henriques, P.D.S. (2011) 'Assessing the prediction capacity of an agricultural supply positive mathematical programming model', Int. J. Sustainable Society, Vol. 3, No. 2, pp.209-220. 
Biographical notes: Rui Manuel de Sousa Fragoso is graduated in Animal Science with a Master in Agricultural Economics and a $\mathrm{PhD}$ in Management. $\mathrm{He}$ is a Member of the Institute of Mediterranean Agricultural and Environmental Sciences (ICAAM), and is an Assistant Professor in the Department of Management at the University of Évora, Portugal. His main research interests are in the field of agribusiness, water economics and operations management. He has participated in several research projects and in cooperation programmes for development.

Maria Leonor da Silva Carvalho is an Engineer in Agronomy with a $\mathrm{PhD}$ in Agricultural Economics. She is a Member of the Institute of Mediterranean Agricultural and Environmental Sciences (ICAAM), and is an Associate Professor in the Department of Economics at the University of Évora, Portugal. Her main research interests include: agricultural economics and policy; rural development; agriculture, natural resources and environment. She has participated in several research projects and in cooperation programmes for development.

Pedro Damião de Sousa Henriques is an Engineer in Agronomy with a Master and a $\mathrm{PhD}$ in Agricultural Economics. He is a Member of the Center for Advanced Studies in Management and Economics (CEFAGE) and an Associate Professor in the Department of Economics, University of Évora, Portugal. His main research interests are in the field of agricultural and resource economics and policies. He has participated in several research projects and in cooperation programmes for development.

\section{Introduction}

Mathematical programming (MP) models have been widely used in the area of agricultural economics, because their structure can be easily adjusted to the economic production theory. Based on an optimization criterion, these models allow representing agricultural production conditions and the analysis of the adjustments due to technical, economic and institutional changes (McCarl and Spreen, 1980). Early applications of MP to agricultural economics aimed to solve and analyse problems related to farm planning (Martin, 1977; Throsby, 1974). These models are simple to formulate and very useful for understanding the actual reality, but have some limitations with regard to supporting decision making and evaluation of agricultural policy and rural development measures. These limitations are mainly due to the need for detailed information to obtain suitable coefficients that describe the production technologies, and the deviation of the optimal values from the observed ones (Heckelei and Britz, 2005).

To approximate the results of the MP models to the observed behaviour, arbitrary constraints are often used that limit their potential of analysis. In this context, positive mathematical programming (PMP) is a feasible alternative that allows automatic calibration of the models without additional constraints (Howitt, 1995). The resulting model can respond, more smoothly, to changes in parameters, making these more consistent with the changes in the observed behaviour. This technique can be understood as a compromise between econometric models and MP models, because parameterisation is based on the observed behaviour, as is the case in econometric models, and the primal solution presents an explicit specification of technology, as is the case in any MP model. 
Recently, the PMP methodology has been often used in the study of economic, social and environmental problems, such as those of modelling the Common Agricultural Policy, namely Arfini et al. (2008) and Blanco and Iglesias (2005).

The objective of this paper is to evaluate the calibration and prediction capacity of a supply response PMP model for the Alentejo region. The model is calibrated with prices and agricultural subsidies of the base year (2000), using four specification rules of the cost function. Then, the model is used to predict agricultural supply of Alentejo region with prices and subsidies of the year 2004.

In the next sections, the PMP and cost function specification rules are discussed. The model of agricultural supply for the Alentejo region is presented, the results are analysed and the conclusions are drawn.

\section{PMP and cost function specification rules}

Even before its formal presentation by Howitt (1995), PMP was used in modelling economic problems applied to the agricultural sector (Bauer and Kasnakoglu, 1990; Horner et al., 1992; House, 1987; Kasnakoglu and Bauer, 1988). After Howitt's article, the interest of its use became more apparent and its importance has increased with introduction of new advancements (Arfini and Paris, 1995; Barkaoui and Butault, 1999; Barkaoui et al., 2001; Cypris, 2000; Gohn and Chantreuil, 1999; Graindorge et al., 2001; Helming et al., 2001).

For a reference situation, PMP allows automatic calibration of models to the observed behaviour (Howitt, 1995). PMP uses the information contained in the dual variables of the constraints of a profit maximisation linear model. The activities of this model are bounded to observed levels, through calibration constraints. Then, dual variables are used to specify a non-linear objective function such that the optimal solution reproduces the observed activity levels.

The empirical procedures of the PMP model consist of two phases, comprising the estimation of the calibration parameters (phase I) and the specification of a non-linear objective function (phase II).

In phase I, a linear programming model is formulated adding to the resource constraints a set of calibration constraints that bound the variables to the observed values in the reference situation. For the case of a profit maximisation problem, the model can be presented as follows:

$$
\begin{aligned}
& \max Z=p^{\prime} x-c^{\prime} x \\
& \text { s.t. } \\
& A x \leq b[\lambda] \\
& x \leq\left(x^{0}+\varepsilon\right)[\rho] \\
& x \geq 0
\end{aligned}
$$

Where $Z=$ objective function value representing the farm profit; $p=(n \times 1)$ vector of product prices; $c=(n \times 1)$ vector of accounting variable costs per unit of activity; $x=(n \times 1)$ vector of production activity levels; $A=(m \times n)$ matrix of coefficients in resource constraints; $b=(m \times 1)$ vector of available resources quantities; $\lambda=(m \times 1)$ vector of dual variables associated with the resource constraints; $x^{0}=(n \times 1)$ vector of 
observed activity levels; $\varepsilon=(n \times 1)$ vector of very small positive numbers to avoid a degenerate dual solution; $\rho=$ dual variables associated with the calibration constraints.

The dual variable vector $\rho$ associated with the calibration constraints can be interpreted as a model miss-specification, data errors, aggregate bias, risk behaviour and price expectation. In the perspective of calibrating a non-linear decreasing yield function, $\rho$ is the difference between the activity average and marginal value products. In the viewpoint of calibrating a non-linear increasing cost function, $\rho$ is a differential marginal cost vector that added to the accounting variable cost vector, $c$ gives the marginal cost of the observed activity levels $\left(x_{0}\right)$.

The vector $\varepsilon$, made of very small positive numbers, prevents the linear dependency between fixed resource constraints and the calibration constraints, avoiding a degenerate dual solution. Hence, at least one of the production activities in this LP model is not only bounded by its calibration constraint, but also by one of the fixed resource constraints. Thus, vector $x$ can be divided into a vector of preferable activities $\left(x^{p}\right)$ bounded by the calibration constraints, and a vector of marginal activities $\left(x^{m}\right)$ that are constrained by the resource constraints.

The dual values of the calibration constraints for preferable activities, marginal activities and resource constraints are given by the Kuhn-Tucker conditions represented in Equations (2)-(4), respectively

$$
\begin{aligned}
& \rho^{p}=p^{p}-c^{p}-A^{p^{\prime}} \lambda \\
& \rho^{m}=[0] \\
& \lambda=\left(p^{m}-c^{m}\right)\left(A^{m^{\prime}}\right)^{-1}
\end{aligned}
$$

In phase II, the dual values of the calibration constraints, $\rho^{\mathrm{p}}$, are used to specify a nonlinear objective function, such that the marginal cost of the preferable activities is equal to the respective price for the observed activity levels in the base year, $x^{0}$. Given these conditions, the model should exactly reproduce the observed vector $x^{0}$.

The quadratic cost function is often used for computational simplicity and because it adjusts well to the hypothesis of decreasing returns in agricultural production:

$$
C^{v}=d^{\prime} x+\frac{1}{2} x^{\prime} Q x
$$

where $d=(n \times 1)$ vector of parameters associated with the linear term; $Q=(n \times n)$ symmetric, positive (semi-) definite matrix with parameters $q_{j j}$, associated with the quadratic term for activities $j$ and $j^{\prime}$.

The marginal variable cost function is the sum of the accounting cost vector $c$ and the differential marginal cost vector $\rho$, and is given by

$$
C m^{v}=\frac{\partial C^{v}\left(x^{0}\right)}{\partial x}=d+Q x^{0}=c+\rho
$$


Given $d$ and $Q$, the non-linear programming problem is as follows:

$$
\begin{aligned}
& \max _{x} Z=p^{\prime} x-d^{\prime} x-\frac{1}{2} x^{\prime} Q x \\
& \text { s.t. } \\
& A x \leq b[\lambda] \\
& x \geq 0
\end{aligned}
$$

This non-linear model without calibration constraints is consistent with the choice of a non-linear cost function, $C^{v}$, and reproduces automatically the observed activity levels as well as the dual values of the limiting fixed resource constraints. The first-order conditions of these dual values in (7) are given by

$$
\lambda=\left(A Q^{-1} A^{\prime}\right)^{-1}\left(A Q^{-1}(p-d)-b\right)
$$

The condition $\mathrm{Cm}=c+\rho$ implies an undetermined system associated with infinite response patterns. Trying to avoid arbitrary simulations of response behaviour, several methods for specification of parameters $d$ and $Q$ of the variable cost function have been developed (Heckelei and Britz, 2005). A short overview of some of these methods is given.

In the first uses of PMP, the specification problem of the quadratic cost function was solved by making $d_{j}=c_{j}$ and setting all off-diagonal elements of the $Q$ matrix to zero. In this approach, called standard specification, the diagonal elements of $Q, q_{j j}$, were calculated as follows:

$$
q_{j j}=\frac{\rho_{j}}{x_{j}^{0}} \quad j=1,2, \ldots, n
$$

Since $\rho^{m}=0$, the standard specification rule leads to a cost function which is linear for marginal activity levels. This implies that a price change of a preferable activity only leads to a substitution of the marginal activity. Basically, the advantages of this method are simplicity of specification and computational ease, mainly when there is a little information available.

Paris (1988) used an alternative specification rule (Paris standard), where the parameter $d$ of the cost function is equal to zero and the elements of the $Q$ matrix are calculated as a function of the explicit observed costs in the base year, $c$, and of the dual values of the calibration constraints, $\rho$, as follows:

$$
d_{j}=0 \text { and } q_{j j}=\frac{c_{j}+\rho_{j}}{x_{j}^{0}} \quad j=1,2, \ldots, n
$$

The diagonal elements of $Q$ for marginal activities are all positive. Hence, a change in preferable activity is not carried out at the expense of the marginal activities, but at that of the other preferable activities.

Another specification of the cost function, named average cost, assumes that the observed vector of the accounting cost per activity unit in the base year, $c$, is equal to the average cost of the quadratic variable cost function and is given as follows:

$$
d_{j}=c_{j}-\rho_{j} \quad j=1,2, \ldots, n \text { and } q_{j j}=\frac{2 \rho_{j}}{x_{j}^{0}} \quad j=1,2, \ldots, n
$$


In this approach, the diagonal elements of $Q$ are larger than those obtained from the standard rule in (9), which implies smaller implicit elasticities. However, the problem of marginal activities with constant returns remains.

Another approach that allows for incorporation of prior information is the exogenous supply elasticities. So with $\partial \mathrm{x} / \partial \mathrm{p}$ equal to $q_{j j}^{-1}$, price elasticity for activity $j$ is calculated by

$$
\varepsilon_{j j}=\frac{1}{q_{j j}} \frac{p_{j}^{0}}{x_{j}^{0}} j=1,2, \ldots, n
$$

The parameters $d_{j}$ and $q_{j j}$ of the cost function are determined as follows:

$$
d_{j}=c_{j}+\rho_{j}-q_{j j} x_{j}^{0} \quad j=1,2, \ldots, n \text { and } q_{j j}=\frac{1}{\varepsilon_{j j}} \frac{p_{j}^{0}}{x_{j}^{0}} \quad j=1,2, \ldots, n
$$

In this case, the exogenous supply elasticities are used to derive the parameters $q_{i j}$ of the diagonal matrix $Q$.

\section{Model of agricultural supply for the Alentejo region}

To analyse the prediction capacity of the considered specification rules for the cost function, the PMP model formulation presented in (7) was adapted to the characteristics of the Alentejo region in southern Portugal. The simplified structure of this model is as follows:

$$
\begin{aligned}
\operatorname{Max} Z= & \sum_{j} p_{j} x_{j}+\sum_{j} a_{j} x_{j}+\sum_{j} p_{j} y_{j}+\sum_{j} a_{j} y_{j} \\
& -\sum_{j} d_{j} x_{j}-\frac{1}{2} \sum_{j} q_{j j} x_{j}^{2}-\sum_{j} d_{j} y_{j}-\frac{1}{2} \sum_{j} q_{j j} y_{j}^{2}-w l-i k
\end{aligned}
$$

s.t.:

$$
\begin{aligned}
& \sum_{j} e_{j f} y_{j} \leq x_{j f} \\
& \sum_{j s} x_{j s}^{*} 0,1 \leq x_{\mathrm{set}} \\
& \sum_{j} x_{j} \leq b_{s} \\
& \sum_{j} h_{j} x_{j}+\sum_{j} h_{j} y_{j} \leq b_{t}+l \\
& \sum_{j} c_{j} x_{j}+\sum_{j} c_{j} y_{j} \leq b_{c}+k
\end{aligned}
$$


where $x_{j}$ and $y_{j}$ are the decision variables concerning $j$ crop activities in hectares (ha) and livestock activities in livestock units; $l$ and $k$ are overtime and additional operation capital units; $p, a, d$ and $h$ are the output value, subsidies, accounting variable costs and work needs per unit of activity $j$, respectively; $w$ and $i$ are the hourly cost of $l$ and the loan annual interest rate of $k ; e_{\mathrm{jf}}$ is the livestock stocking rates and $b_{s}, b_{t}$ and $b_{c}$ are the fixed resources of land, work and capital availability.

The objective function (13) maximises the gross margin in euros and is calculated as the difference between the revenue and the total variable costs. The revenue includes agricultural output values and direct subsidies. The variable costs incorporate short-time linear input costs $\left(d_{j}\right)$, costs of overtime work $(w)$, operating capital $(i)$ and also marginal costs' coefficients of agricultural activities $\left(q_{i j}\right)$.

The decision variables in the model include 18 agricultural crops and livestock activities in the Alentejo region. The crop activities consist of cereals and oil seeds, horticulture and fruit cultures, fruit trees, vineyards, olive trees, permanent pastures, forage, compulsory set-aside, fallow and an activity for land occupied by forests. The livestock activities consist of beef cattle, sheep and extensive swine.

Permanent pastures and forage are intermediate activities, because they are not sold but are an input for livestock activities. Therefore, these activities are only associated with costs as their profits are indirectly obtained from the animal activities. The profit transfer between activities is given essentially in Equation (14) that defines the balance between forage areas $\left(x_{j j}\right)$ and the total number of animals.

Equation (15) models the set-aside $\left(x_{\text {set }}\right)$ imposed by CAP. This equation states that $10 \%$ of the crop area $\left(x_{j s}\right)$ has to be relieved from production and put in set-aside. Equations (16)-(18) concern land use, labour and capital. These equations state that the resource demand is less than or equal to its availability.

In spite of the objective function representing a return to land, labour and capital, the model solution is only limited by land availability as given in (16). Given the labour (17) and the capital (18), the demand can exceed their availabilities by purchasing additional work hours at an hourly cost of $€ 3.5$ and additional units of capital at an annual interest rate of $7 \%$.

The results of the PMP model for agricultural supply in the Alentejo region were obtained for each one of the specification rules of the cost function. Hence, the objective function (13) has changed according with the formulations presented in (9)-(12).

The different formulations of the objective function used for each specification rule of the cost function are shown in Appendix.

\section{Results}

The model for the agricultural supply of the Alentejo region was solved for each one of the specification rules of the cost function. First, each one of the PMP models was calibrated for the base year (2000). Then, the model was used to predict agricultural supply with prices and subsidies of the year 2004. In both cases, the results were compared with available data for crop areas and livestock units in the Alentejo region for the years 2000 and 2004, respectively.

As expected, for the base year, the results of the PMP model reproduce exactly the observed level of the activities, regardless the specification rule of the cost function. In the calibration phase, the different specification approaches of the cost function give the 
same results, because the condition $\mathrm{Cm}=c+\rho$ constitutes an undetermined system. So there are infinite numbers of values for parameters $q_{i j}$, satisfying the conditions of the PMP problem.

To assess the prediction capacity of PMP model and of the cost function specification rules, the percentage absolute deviation (PAD) is used. PAD is calculated as the difference between model results and the observed activity levels in 2004 (Table 1). This table also presents the total weighted absolute deviation, which takes into account the relative weight of each crop on the total land area and of each animal activity on the total livestock units.

When the exogenous elasticities approach is used, only three activities have an absolute deviation above the $15 \%$ indicated by Hazell and Norton (1986) as the maximum value for a desirable calibration. These activities are rice $(-23.5 \%)$, sunflower $(76.4 \%)$ and vine $(-48.6 \%)$. The observed area values of these activities, for the years 2000 and 2004, did not change, except for the area of vineyard which increased slightly.

For Paris standard rule, there are six activities that present absolute deviations above $15 \%$, four crop and two livestock activities. The absolute deviations observed for the area of common wheat (109.9\%) and sunflower (63.7\%) are particularly large; with regard to livestock activities, the absolute deviation of $20.9 \%$ for beef cattle determines a larger increase of this activity than that which actually occurred in the beef cattle sector.

Table 1 PAD for activity levels in 2004

\begin{tabular}{lrrrc}
\hline & & & & Exogenous \\
& Standard & Paris standard & Average cost & elasticities \\
\hline Common wheat & -26.6 & 109.9 & 81.8 & -7.3 \\
Durum wheat & -12.6 & -11.2 & -10.5 & -11.5 \\
Maize & -11.4 & -8.3 & -9.1 & -9.9 \\
Rice & -65.2 & -19.5 & -36.6 & -23.5 \\
Horticulture & 18.4 & 11.0 & 11.4 & 10.4 \\
Sunflower & 51.9 & 63.7 & 62.5 & 76.4 \\
Olive trees & -100.0 & -0.8 & -53.4 & 11.1 \\
Vineyard & -36.2 & -35.3 & -33.2 & -48.6 \\
Fruits & -7.3 & -8.7 & 0.0 & -5.5 \\
Permanent pastures & 44.3 & 2.0 & 23.9 & -3.4 \\
Forage & 44.3 & 2.0 & 23.9 & -3.4 \\
Fallow & -79.9 & -10.7 & -49.7 & 6.3 \\
Forests & 4.1 & 4.1 & 4.1 & 4.1 \\
Set-aside & -5.4 & 10.5 & 8.1 & 0.6 \\
Beef cattle & 88.7 & 20.9 & 38.1 & 4.2 \\
Sheep & 5.5 & 4.7 & 7.0 & 11.3 \\
Swine & 271.8 & 12.6 & 258.5 & 15.8 \\
Weighted absolute deviation: crop activities & 39.2 & 8.3 & 26.2 & 7.3 \\
Livestock activities & 88.0 & 14.4 & 63.4 & 7.8 \\
\hline Source: INE (2000-2005) and PMP model & & & \\
\hline
\end{tabular}

Source: INE (2000-2005) and PMP model results. 
Regarding the standard and average cost specification rules, ten activities show absolute deviations above $15 \%$. Animal activities have a particularly high absolute deviation; for instance, extensive swine production has an absolute deviation greater than $200 \%$. Intermediate activities of pasture and forage have also large absolute deviations.

The variability of the results obtained with the different specification rules of the cost function can be explained through implicit supply elasticities in each crop or animal activity (Table 2).

The specification rules of standard and average cost present, on average, the largest implicit supply elasticities for activities and their results are further from the observed real values, and thus have the worst prediction capacity.

The results obtained from the specification rule of exogenous elasticities and Paris standard have smaller values, on average, for implicit supply elasticities, and therefore these are the rules that present the best prediction capacity for the results of the year 2004.

Table 2 Supply elasticity of agricultural activities

\begin{tabular}{lcccc}
\hline & Standard & Paris standard & Average cost & $\begin{array}{c}\text { Exogenous } \\
\text { elasticities }\end{array}$ \\
\hline Common wheat & 4.68 & 1.77 & 1.33 & 4.05 \\
Durum wheat & 11.22 & 3.71 & 7.42 & 7.42 \\
Maize & 0.11 & 0.00 & 0.00 & 0.00 \\
Rice & 6.04 & 2.26 & 0.00 & 0.00 \\
Horticulture and fruit culture & 4.08 & 5.10 & 0.00 & 0.00 \\
Sunflower & 8.33 & 5.32 & 2.66 & 0.00 \\
Olive tree & 51.00 & 14.19 & 1.15 & 1.81 \\
Vineyard & 0.00 & 0.00 & 0.00 & 8.50 \\
Fruits & 14.47 & 14.47 & 14.47 & 14.47 \\
Set-aside & 1.79 & 1.51 & 1.51 & 1.51 \\
Forests & 0.00 & 0.00 & 0.00 & 0.00 \\
Beef cattle & 2.63 & 1.66 & 0.99 & 0.37 \\
Sheep & 1.11 & 0.77 & 1.27 & 0.16 \\
Swine & $\infty$ & $\infty$ & $\infty$ & $\infty$ \\
\hline Source PMP & & & & \\
\hline
\end{tabular}

Source: PMP model results.

\section{Conclusions}

In general, MP models aim to evaluate economic, technical and institutional scenarios, implying changes in prices, technologies and available inputs. Their quality is checked by sensitivity and post-optimal analysis to changes in their coefficients.

In this context, this paper evaluates the calibration and prediction capacities of a PMP model, developed for the agricultural supply conditions of the Alentejo region. The considered cost function specification rules were standard, Paris standard, average cost and exogenous elasticities. 
The results show that the PMP model reproduces exactly the observed activity levels for the base year, regardless of the rule used to specify the cost function. Regarding the model prediction capacity, i.e. the simulation behaviour of the model, PMP reveals to be a feasible methodological option, mainly if exogenous elasticities or Paris standard approaches are used to specify the cost function. The specification rules of cost function based on standard method and on average cost method show a weaker prediction capacity, and present, on average, large implicit supply elasticities for agricultural activities.

Gocht (2005) investigated the simulation behaviour of PMP models, and his results also showed that the exogenous elasticities presented one of the lowest PAD among the different calibration methods used. In summary, PMP can be used not only to exact calibration of models, but also to predict agricultural supply under different scenarios.

\section{References}

Arfini, F., Donati, M., Grossi, L. and Paris, Q. (2008) 'Revenue and cost function in PMP: a methodological integration for a territorial analysis of CAP', Modelling Agricultural and Rural Development Policies, Proceedings of the 107th Seminar, 29 January-1 February 2008, Sevilla, pp.305-321.

Arfini, F. and Paris, Q. (1995) 'A positive mathematical programming model for regional analysis of agricultural policies', in E. Sotte (Ed.), The Regional Dimension in Agricultural Economics and Policies, EAAE, Proceedings of the 40th Seminar, 26-28 June 1995, Ancona, pp.17-35.

Barkaoui, A. and Butault, J. (1999) 'Positive mathematical programming and cereals and oilseeds supply with EU under Agenda 2000', Paper presented at the 9th European Congress of Agricultural Economists, Warsaw.

Barkaoui, A., Butault, J. and Rousselle, J. (2001) 'Positive mathematical programming and agricultural supply within EU under Agenda 2000', in T. Heckelei, H.D. Witzke and W. Henrichsmeyer (Eds.), Agricultural Sector Modelling and Policy Information System, Proceedings of the 65th EAAE Seminar, 29-31 March, Bonn University, Vauk Verlag Kiel.

Bauer, S. and Kasnakoglu, H. (1990) 'Non linear programming models for sector policy analysis', Economic Modelling, Vol. 7, pp.272-290.

Blanco, M. and Iglesias, E. (2005) 'Modelling new EU agricultural policies: global guidelines, local strategies', in F. Arfini (Ed.), Modelling Agricultural Policies: State of the Art and New Challenges, Proceedings of the 89th European Seminar of the EAAE, 3-5 February 2005, Parma, pp.831-843.

Cypris, C. (2000) 'Positiv mathematische programmierung (PMP) im Agrarsektormodells RAUMIS', Dissertation, University of Bonn.

Gocht, A. (2005) 'Assessment of simulation behavior of different mathematical programming approaches', in F. Arfini (Ed.), Modelling Agricultural Policies: State of the Art and New Challenges, Proceedings of the 89th European Seminar of the EAAE, 3-5 February 2005, Parma, pp.166-187.

Gohn, A. and Chantreuil, F. (1999) 'La programmation mathématique positive dans les modèles d'exploitation agricole. Principes et l'importance du calibrage', Cahiers d'Economie et de Sociologie Rurales, Vol. 5, pp.59-79.

Graindorge, C., Henry de Frahan, B. and Howitt, R. (2001) 'Analysing the effects of Agenda 2000 using a CES calibrated model of Belgian agriculture 2001', in T. Heckelei, H.D. Witzke and W. Henrichsmeyer (Eds.), Agricultural Sector Modelling and Policy Information System, Proceedings of the 65 ${ }^{\text {th }}$ EAAE Seminar, 29-31 March, Bonn University, Vauk Verlag Kiel, 2001, pp.176-186.

Hazell, P.B.R. and Norton R.D. (1986) Mathematical Programming for Economic Analysis in Agriculture. New York: Macmillan Publishing Company. 
Heckelei, T. and Britz, W. (2005) 'Models based on positive mathematical programming: state of the art and further extensions', in F. Arfini (Ed.), Modelling Agricultural Policies: State of the Art and New Challenges, Proceedings of the 89th European Seminar of the EAAE, 3-5 February 2005, Parma, pp.48-73.

Helming, J., Peeters, L. and Veendendaal, P. (2001) 'Assessing the consequences of environmental policy scenarios in flemish agriculture', in T. Heckelei, H.D. Witzke and W. Henrichsmeyer (Eds.), Agricultural Sector Modelling and Policy Information System, Proceedings of the 65th EAAE Seminar, 29-31 March 2000, Bonn University, Vauk Verlag Kiel, pp.237-245.

Horner, G., Corman, J., Howitt, R., Carter, C. and MacGregor, R. (1992) 'The Canadian regional agriculture model: structure, operation and development, agriculture, Canada', Technical Report 1/92, Ottawa.

House, R. (1987) USMP Regional Agricultural Model. Washington, DC: USDA. National Economics Division Report, ERS, 30.

Howitt, R. (1995) 'Positive mathematical programming', American Journal of Agricultural Economics, Vol. 77, No. 2, pp.329-342.

Instituto Nacional de Estatística (2000-2005): Estatísticas Agrícolas.

Kasnakoglu, H. and Bauer, S. (1988) 'Concept and application of an agricultural sector model for policy analysis in Turkey', in S. Bauer and W. Henrichsmeyer (Eds.), Agricultural Sector Modelling. Vauk Verlag: Kiel.

Martin, L.R. (1977) A Survey of Agricultural Economics Literature, Vol. 2, Minneapolis: University of Minnesota Press.

McCarl, B. and Spreen, T. (1980) 'Price endogenous mathematical programming as a tool for sector analysis', American Journal of Agricultural Economics, pp.87-102.

Paris, Q. (1988) PQP, PMP, Parametric Programming and Comparative Static. Chapter 11 in Notes for AE 253. Department of Agricultural Economics, University of California, Davis.

Throsby, C.D. (1974) 'New methodologies in agricultural production economics: a review in the future of agriculture', Papers and Reports, 15th International Conference of Agricultural Economics, S. Paulo, Brazil, pp.150-169. 


\section{Appendix}

Formulation of the objective function according to the considered specification rules of the cost function

Standard formulation:

$$
\begin{aligned}
\operatorname{Max} Z= & \sum_{j} p_{j} x_{j}+\sum_{j} a_{j} x_{j}+\sum_{j} p_{j} y_{j}+\sum_{j} a_{j} y_{j} \\
& -\sum_{j} c_{j} x_{j}-\frac{1}{2} \sum_{j} \frac{\rho_{j}}{x_{j}^{0}} x_{j}^{2}-\sum_{j} c_{j} y_{j}-\frac{1}{2} \sum_{j} \frac{\rho_{j}}{y_{j}^{0}} y_{j}^{2}-w l-i k
\end{aligned}
$$

Paris standard formulation:

$$
\begin{aligned}
\operatorname{Max} Z= & \sum_{j} p_{j} x_{j}+\sum_{j} a_{j} x_{j}+\sum_{j} p_{j} y_{j}+\sum_{j} a_{j} y_{j} \\
& -\frac{1}{2} \sum_{j} \frac{c_{j}+\rho_{j}}{x_{j}^{0}} x_{j}^{2}-\frac{1}{2} \sum_{j} \frac{c_{j}+\rho_{j}}{y_{j}^{0}} y_{j}^{2}-w l-i k
\end{aligned}
$$

Average cost formulation:

$$
\begin{aligned}
\operatorname{Max} Z= & \sum_{j} p_{j} x_{j}+\sum_{j} a_{j} x_{j}+\sum_{j} p_{j} y_{j}+\sum_{j} a_{j} y_{j} \\
& -\sum_{j}\left(c_{j}-\rho_{j}\right) x_{j}-\frac{1}{2} \sum_{j} \frac{2 \rho_{j}}{x_{j}^{0}} x_{j}^{2}-\sum_{j}\left(c_{j}-\rho_{j}\right) y_{j}-\frac{1}{2} \sum_{j} \frac{2 \rho_{j}}{y_{j}^{0}} y_{j}^{2}-w l-i k
\end{aligned}
$$

Exogenous supply elasticities formulation:

$$
\begin{aligned}
\operatorname{Max} Z= & \sum_{j} p_{j} x_{j}+\sum_{j} a_{j} x_{j}+\sum_{j} p_{j} y_{j}+\sum_{j} a_{j} y_{j} \\
& -\sum_{j}\left(c_{j}+\rho_{j}-\frac{1}{\varepsilon_{j j}} \frac{p_{j}^{0}}{x_{j}^{0}}\right) x_{j}-\frac{1}{2} \sum_{j} \frac{1}{\varepsilon_{j j}} \frac{p_{j}^{0}}{x_{j}^{0}} x_{j}^{2} \\
& -\sum_{j}\left(c_{j}+\rho_{j}-\frac{1}{\varepsilon_{j j}} \frac{p_{j}^{0}}{y_{j}^{0}}\right) y_{j}-\frac{1}{2} \sum_{j} \frac{1}{\varepsilon_{j j}} \frac{p_{j}^{0}}{y_{j}^{0}} y_{j}^{2}-w l-i k
\end{aligned}
$$

